\title{
Stranger than Fiction? A Few Methodological Notes on Linguistic Research in Film Discourse
}

\begin{abstract}
This theoretical essay addresses a number of methodological problems pertinent to linguistic research on film discourse. First of all, attention is paid to the interdependence between contemporary film discourse and everyday language, with a view to dispersing doubts about the former's legitimacy in language studies. Also, the discussion captures the interface between a character's identity portrayal and the target audience's socio-cultural background and expectations. Another objective is to elaborate a model of film discourse's twofold layering, viz. the fictional layer and the film crew's layer; and two communicative levels, namely the characters' level and the viewer's level, on which meanings are communicated and inferred by the viewer, who is conceptualised as the recipient. Additionally, the notion of recipient design will be endorsed in order to demonstrate that meanings are purposefully communicated to, and thus gleaned by, the viewer. Several postulates are propounded concerning the viewer's understanding and appreciation of film discourse.
\end{abstract}

Key words

Communicative level; film discourse; identity construction/representation; layering; recipient; recipient design

\section{Film discourse}

The term film discourse (or film talk) is here used in reference to fictional characters' communication in feature films, as well as in series and serials (even though, technically speaking, the two are not films). Characters' discourse is comprised of verbalisations, coupled with non-verbal communication (NVC), which can be defined in a broad sense and in a narrow sense. 
"While in broad definitions NVC includes any kind of non-verbal messages (or non-verbal signs) proper to informative processes, more narrow definitions restrict it to non-language (or better non-linguistic) phenomena that are interrelated - often in an intricate way - with verbal language and can be found in interactive or communicative processes." (Payrató 2009: 164)

Here the broad view is advocated, on the understanding that body language, such as gestures and facial expression, together with vocalics, both captured by the narrow definition, is a significant subtype of NVC. Even in the broad sense, NVC should not be mistaken for visual communication pivoted on cinematographic techniques, affecting the way interactions are presented on the screen.

Film discourse is here viewed as conflating monologues, dialogues, i.e. dyadic interactions, and polylogues, i.e. exchanges held by more than two participants, similar to those found in everyday talk (cf. Kerbrat-Orecchioni 1997, 2004). However, as Chovanec (2011) rightly indicates, whilst in common parlance the term "dialogue" refers to dyadic conversations, i.e. conversations held by two people, in accordance with the Greek etymology ("dia-", i.e. "across", and "legein", i.e. "speak"), it pertains to talk held by two or more participants. While etymologically unfounded, the understanding of dialogue as synonymous with dyadic conversation is widespread both in dictionary definitions and in the literature of the topic, which is why it is also supported here. A distinction is then drawn between dialogues and polylogues, the latter capturing conversations of more than two people. The adoption of this terminology also necessitates the rejection of the common term "film dialogue" used in reference to two or more film characters' verbal interactions. For the sake of terminological clarity, a distinction is here drawn between film dialogue and film polylogue.

Film discourse is not to be mistaken for cinematic discourse, which conflates an array of cinematographic techniques, which are studied primarily outside linguistics. Nonetheless, film discourse, as perceived by the viewer, is the collaborative work of the whole film crew, here dubbed the collective sender. Film talk, as listened to (and watched) by the viewer, is affected by the whole gamut of cinematographic techniques, the result of collective sender's work, embracing among others: the scriptwriter, the director, camera operators, actors, picture and sound editors. Therefore, there are numerous factors, such as the quality of shots, camera angle or editing, which contribute to the communicative effect the crew promotes for the viewer's benefit.

Authors (Kozloff 2000, Richardson 2010) of rare monographs on film dialogue (a term not supported here, inasmuch as it may suggest dyadic interactions only) lament the prevalent bias in film studies in favour of visually communicated meanings, which results in the underestimation of film language in scholarly linguistic works. Despite the elapsing time, the literature on the nature of film discourse is still scarce (e.g. Kozloff 2000; Culpeper 2001; Bubel 2006, 2008; Bubel and Spitz 2008; Quaglio 2008, 2009; Richardson 2010; Dynel 2010a, 2010b, 2011d, 2011e). The majority of scholarship on cinema falls outside lin- 
guistic research, and focuses almost exclusively on film criticism or cinematic discourse/language, addressing multimodal, cinematographic techniques (e.g. Bordwell and Thompson 1979, Aumont et al. 1992, Monaco 1981, Stam 2000, Giannetti 2007).

\section{Film discourse and real language use}

Film discourse can be conceptualised as fictional/non-authentic/scripted ${ }^{1}$ conversations held by fictional ${ }^{2}$ characters and happens to be captured under such epithets as "scripted" "constructed" or "prefabricated" dialogue (Chovanec 2011) or polylogue. Referring to theatrical interactions, Chothia (1978) rightly observes their dichotomous nature, typical also of film discourse.

"Stage dialogue is different from real speech. It operates by duplicity: it is not spontaneous but must appear to be so. It is permanent but must appear to be as ephemeral as the speech it imitates. The actor must seem to speak what in reality he recites. In sharing the convention, the audience in the theatre has a share in the duplicity. We simultaneously accept the illusion of spontaneity and know that it is a pretense." (Chothia 1978: 7-8)

A number of dichotomies between fictional and real/real-life/non-fictional/ordinary/everyday discourse can be detected, such as spontaneity vs. meticulous preparation, permanence vs. ephemeral nature, or the speaker's intentional communication vs. the speaker's reproduction of words. Admittedly, it is because of such discrepancies that researchers are in dispute over the applicability of film discourse in linguistic analyses. Some argue that if film discourse is fabricated, it must be anti-empirical (e.g. Schegloff 1988, Emmison 1993), inasmuch as it "has been scripted, written and rewritten, censored, polished, rehearsed, and performed" (Kozloff 2000: 18).

On the other hand, film discourse set in contemporary times should mirror language users' everyday communicative patterns, evoking an illusion of reallife conversations, and subscribing to the so-called "reality code" or "cultural realism" (e.g. Berliner 1999, cf. Kozloff 2000, Richardson 2010). This notion means that a film script should adhere to "a complex code of what a culture at a given time agrees to accept as plausible, everyday, authentic" (Kozloff 2000: 47). Scriptwriters are "cultural interpreters" (Newcomb and Hirsch 1987: 458), articulating "the main lines of the cultural consensus about the nature of reality" (Fiske and Hartley 1978: 602). They must take account of the surrounding reality, inclusive of the nature of communication and language use. The skill of the writer and other crew members manifests itself in the verisimilitude of fictional interactions. To reformulate, characters' verbalisations are constructed to resemble realistic language use (Georgakopoulou 2000), being thus "a canonical approximation of spontaneous talk in interaction" (Boxer 2002: 18). Herman (1995) addresses the 
interface between real and dramatic language, which bears relevance to film discourse, as well.

"The principles, norms and conventions of use which underlie spontaneous communication in everyday life are precisely those which are exploited and manipulated by dramatists in their constructions of speech types and forms in plays. Thus, 'ordinary speech' or, more accurately, the 'rules' underlying the orderly and meaningful exchange of speech in everyday contexts are the resource that dramatists use to construct dialogue in plays."

(Herman 1995: 6)

Ordinary linguistic principles and conventions underlying regular language use guide scriptwriters of theatrical plays and films (who are also language users, even if more sensitive to forms of expression) in the construction of characters' interactions. Couched in the same linguistic resources, whether reproduced by actors portraying characters or produced by ordinary language users in real life, utterances serve the same, albeit diversified, communicative interpersonal functions, such as relaying messages, or self-presentation.

"Represented talk [...] is, like its real-world analogue, more or less coded and calculated for interpersonal effect. Social encounters are not just events in the realization of story structures, but also moments in the characters' relationships with one another. [...] These displays are crafted, whether by instinct or by more conscious awareness of what sorts of things are possible [...], from the same resources that are generally available to language users." (Richardson 2010: 106)

Whether intuitively employed by regular language users or carefully constructed by a script writer and then rendered by actors under the director's supervision, an interaction always operates on the same linguistic resources, in accordance with deeply ingrained, and frequently only intuitively felt, communication rules. It is also noteworthy that fictional discourse tends to permeate real discourse, for individual speakers incorporate textual chunks from films into their idiolects (Kozloff 2000, Richardson 2010), using them as allusion-based witticisms (Dynel 2011a).

Film discourse presents numerous features typifying real interactions, while its "naturalness" shows in that it can be interpreted with theories proposed for ordinary communication, and the workings of linguistic theories can be verified in analyses of fictional talk. Therefore, reminiscent of non-fictional discourse in various respects, fictional verbal and non-verbal communication can be successfully discussed in the light of various linguistic proposals (cf. Simpson 1998, Short 1981/1989, Culpeper 2001, Quaglio 2009, Richardson 2010). For instance, identity construction studies tend to be anchored in the speech act theory (Hurst 1987, Lowe 1998, Short 2007), in which authors endorse a view that certain characters 
have a tendency towards producing particular speech act types. Other authors (Cooper 1981, Short 1981/1989, Bennison 1993) recruit the Gricean account to dissect the workings of characters' utterances couched in implicatures emerging from maxim flouts. It is also hardly surprising that linguists should have recourse to fictional dialogues and polylogues as data to illustrate contemporary communicative practices, presupposing or even arguing in favour of the similarity between real and fictional language use (e.g. Goffman 1974; Tannen 1984; McHoul 1987; Carter and Simpson 1989; Herman 1995, Tannen and Lakoff 1994, Hopper and Le Baron 1999; Weatherall 1996; Emmison and Goldman 1996; Georgakopoulou 2000; Rose 2001; Bubel and Spitz 2008; Bubel 2006, 2008).

Nonetheless, in fairness to critics who harbour doubts as regards the comparability between film discourse and everyday language, a provision must be made that research questions need to be chosen with care. Irrespective of the points of resemblance they share with everyday talk, verbal interactions in films (representing a variety of genres) may display features which will not normally be found in the former, at least not to the same degree. For instance, based on a comparative corpus study, Quaglio (2009) adduces evidence that the discourse of a sitcom, "Friends", bears numerous similarities to naturally occurring conversations. However, several differences are observed as well, with film talk being less vague, suffused with linguistic markers of emotionality and informativeness, but presenting lesser narrativity. These differences can be attributed, most likely, to constraints on interaction types and topics (Quaglio 2009).

While minor differences may pass unnoticed from the vantage point of a regular film viewer, they may be crucial for some language studies. For instance, mispronunciations, overlaps or self-corrections with which real-life discourse is replete will be scarce in films (Richardson 2010), so that the viewer's understanding is not impeded or even precluded. Nota bene, if a given role or interaction demands this, such communicative obstacles will obviously be found in film discourse, serving as a testament to skills and expertise of the scriptwriter, the actor and the director. It is worth noting that many memorable portrayals in the history of cinema are those of characters with retardation and speech impediments, Leonardo DiCaprio's portrayal of Arnie Grape in "What's Eating Gilbert Grape" or Tom Hanks's role of the eponymous Forrest Gump being just two examples.

In addition, film genres may exhibit communicative tendencies which are not commonplace in non-fictional discourse. For instance, comedies abound in repartee and contests of wit (cf. Kozloff 2000), which do occur in everyday conversations, albeit with lower frequency. Consequently, it would be ill-advised to conduct sociolinguistic quantitative humour research on the basis of fictional discourse. Needless to say, no such problems arise when examples quoted from films illustrate postulates of a non-sociological nature, e.g. semantic, cognitive or pragmatic ones (e.g. see Dynel 2009, 2010a, 2010b), or when film dialogues and polylogues are analysed as film discourse, without any hypothesis being advanced concerning real language use (e.g. Bubel 2006, 2008; Bubel and Spitz 2008). 
Potential lack of full similarity to real-life discourse may also emerge from the fact that fictional conversations must be available and comprehensible to viewers, which is why all requisite information must be sneaked into interactions (Richardson 2010), even if interlocutors might not need to communicate such meanings to one another. Nevertheless, this goal can be attained cleverly, so that characters' utterances do not sound artificial or stilted. Scripted utterances need to sound plausible in characters' mouths, as viewers should engage in the plot and, for the duration of the screening, suspend the presumption that utterances are authored by parties different from the ones that produce them within the fictional reality. Phoney language use should not be mistaken for deliberate violation of communicative patterns by characters (as designed by scriptwriters), a case in point being Dr House's unprecedented abrasiveness and impoliteness towards his patients and co-workers, untypical of any professional, which can be explained as being oriented towards entertaining the general audience. Viewers can take a character's communicative patterns in their stride and never question them. Although displaying their own quirks and idiosyncrasies, characters normally come across as being plausible if they are coherently portrayed, e.g. via their consistent idiolects.

\section{Identity construction of characters}

Apart from supplying plot themes, film dialogues and polylogues serve a variety of functions (cf. Kozloff 2000). Most importantly, they help construct character identities and relations, which are (whether or not consciously) duly generated by lay viewers and which can be studied by language researchers (cf. Culpeper 2001, 2002; Bubel 2006, 2008; Bubel and Spitz 2008; Dynel 2010a, 2011d). Characterisation, representation or identity construction, whether in literary works (so far most abundantly described), plays or films, can be defined as a complex account of an individual's utterances, actions, wants, beliefs, etc. (Downes 1988). Numerous studies representing diversified theoretical approaches have been devoted to the problem of identity construction, whether of real people or fictional characters, most frequently literary (e.g. Garvey 1978; Phelan 1979; Margolin 1983, 1996; Schwarz 1989; Fokkema 1991; Scholes and Kellogg 1966; Walcutt 1966; Palmer 2002; Semino 2002; Antaki and Widdicombe 1998; Turner and Oakes 1989; Palmer 2004; Bucholtz and Hall 2005; Martin and White 2005).

Support is here given to the humanising approach, rather than the de-humanising approach, to a character's identity construction known in literature studies (cf. Culpeper 2001). Admittedly, the former perspective should be assumed in linguistic research, because it capitalises on knowledge from psychology, sociology, as well as linguistic research on human communication, affording profound insight into characterisation strategies. The fundamental premise of this approach is that recipients "recognise, understand and appreciate fictional characters insofar as their appearances, actions and speech reflect or refer to those of persons in 
real life" (Mead 1990: 442). Needless to say, image management lies at the heart of all human encounters, with language playing a crucial role in it. In everyday communication, interactants deploy image politics and develop opinions of one another on the basis of their linguistic communicative patterns.

"Language is an intrinsic component of personality. Linguistic style is an outgrowth of psychological style, and a diagnostic of it as well. We assume that the way people talk tells us the truth about them." (Lakoff 1990: 257)

The same appears to be pertinent to film discourse, where

"the linguistic organisation of a text will predetermine to a certain degree the kind of 'picture' one may compose of a protagonist. Therefore the particular forms by which this is achieved need to be studied in detail.

(van Peer 1989: 9)

Although fictional characters may be representatives of classic dramatic roles (e.g. Propp 1968, Greimas 1966/1983, Frye 1957), they are primarily portrayed as being "real people", i.e. prototypical members of social categories (Culpeper 2001). Among other issues, contemporary films need to respond to social changes in order to capture prevalent representations of human social types known to an audience, simultaneously helping to define them (Dow 1996). The appreciation of fictional characters (whether in a literary work or in film discourse), their actions, motives and utterances is conducted according to top-down and bottom-up processes. All incoming stimuli about an individual are processed in the light of each interpreter's real-life experiences and background knowledge of the real world and the fictional world (Culler 1975, Toolan 1988, Emmott 1997, Culpeper 2001). Repetitive patterns in people's verbal and nonverbal expression lead to stereotypes or simply prevailing means of communication, which foster expectations as to how people communicate, e.g. depending on their gender and social background. These default conventions should be mirrored in contemporary film discourse to promote viewers' perception of reality on the screen. Therefore, the language of popular culture texts may also reinforce stereotypical beliefs and attitudes (Berger 1992). On the other hand, media discourse, even if fictional, can affect the shape of the contemporary culture, sometimes introducing societal trends, initially foreign to viewers, i.e. society members, who duly incorporate promoted social schemata into their construction of self and others (cf. Hedley 2002). A shiny example is Carrie Bradshaw, a character from "Sex and the City", who appears have broken the mould and become the epitome of a commodity post-feminist, (regrettably) serving as a role model for many a European woman.

In essence, media identity construction both reflects and shapes the viewer's understanding of social categories (Gauntlett 2002, Bignell 2002) implemented by dint of verbal and nonverbal techniques, manifesting themselves in how characters communicate with one another. It is perhaps not so much the plot (which 
may border on the absurd) as the coherent portrayal of characters, inclusive of their plausible idiolects, that appears to be of immediate relevance to the creation of the aura of plausibility in films.

On the other hand, it may be argued that to sustain realism, characters are burdened with peculiar or infrequent problems, quirks and foibles, testifying that no two individuals can be identical. A reservation must be made, however, that there are also characters "larger than life", whom Harvey (1965) labels as "cards" and who will display exaggerated, far-fetched features, which Culpeper (2001) dubs "prototypicality distortions". Such characters frequently recur in comedies and sitcoms, whose humour resides (among others) in protagonists' idiosyncrasies. This is the case of the neurotic Melvin Udall portrayed by Jack Nicholson in "As Good as It Gets", or Patricia Routledge's Hyacinth Bucket in "Keeping up Appearances", who will go to any lengths to earn the reputation of being a member of the upper crust. Aptly portrayed, characters in fictional discourse, whether or not based on real people (in the case of biographical films) come over as being plausible, regardless of other features of the plot.

\section{Twofold layering and two communicative levels}

Resorting to different terminologies, several authors (e.g. Burger 1984, 1991; Bell 1991; Scannell 1991; Fetzer 2006) argue that media talk inherently rests on what is here called two levels of communication or communicative levels, entailing different hearers. Those can be dichotomised into listeners shown on the screen and viewers, for whose benefit televised interactions take place (Dynel 2010a, 2011b, 2011c, 2011e). In essence, in televised programmes, interactants communicate with one another, assuming that they are constructing discourse for viewers' benefit, and sometimes even addressing the latter (Goffman 1981, Fetzer 2006, O'Keeffe 2006). Consequently, TV viewers of broadcast talk are acknowledged as being ratified recipients (e.g. Goffman 1981; Bell 1984; Scannell 1991; Fetzer 2006; O'Keeffe 2006; Hutchby 2006; Lorenzo-Dus 2009, cf. Dynel 2000b, 2011c, 2011e). Similarly, viewers of film (and drama) discourse can also be deemed as ratified hearers (e.g. Short 1981/1989, 1994; Bubel 2006, 2008; Dynel 2010a, 2011e). On the other hand, none of the models proposed for the two-levelled broadcast talk can capture the nature of fictional communication in films. Although such frameworks may acknowledge the production team's impact on the form of broadcast talk prepared especially for the viewer, they fail to capture fictional discourse, for it is rendered by the whole film production team and is not the product of interlocutors (even if interactions in televised programmes can be pre-planned).

Authors frequently conceive film audiences as overhearers or eavesdroppers, yet rightly appreciating that fictional film discourse is constructed especially for them (Kozloff 2000; Bubel 2006, 2008; Richardson 2010). Indeed, viewers are the primary ratified participants in film discourse. To avoid ambivalent terminol- 
ogy (inasmuch as overhearers and eavesdroppers are inherently unratified), the term "recipients" is championed instead. The concept, as long as not used in reference to any other hearer type, is a tenable technical term capturing viewers. It is proposed as a theoretical construct, rather than being used in the ordinary sense of the word, as done by lay language users or even researchers into media studies who do not concentrate on hearer roles. Also, even though the focus is on the recipient's listening to film discourse, rather than the viewing process, it must be appreciated that verbal interactions on the screen are also watched. The term "recipient", put forward primarily as a hearer category, is not counter-intuitive also when applied to visual communication. Moreover, the concept of metarecipient is proposed. Technically, a subtype of the recipient, the metarecipient, who can be a researcher or film critic, enjoys a better informed position, consciously analysing (chosen elements of) the form and content of the collective sender's product, inclusive of its discourse (Dynel 2010a). It should also be noted that regular recipients may also show some expertise typical of metarecipients and, when watching films for pleasure, take cognisance of chosen strategies deployed by the collective sender.

As regards communicative levels in fictional discourse, Short (1981/1989, 1994), discusses embedding in dramatic discourse, which operates on the playwright's message to the audience at one level, and a character addressing another at the other one. This model, however, does not explicitly allow for other factors: the impact of the production crew's work on the viewer's perception of staged interactions (Bubel 2006, 2008). Nor does it take account of the role of the viewer in the process of meaning derivation (cf. Bubel 2006, 2008). Furthermore, as Clark (1996) emphasises, the metaphorical concept of embedding wrongly suggests that the fictional level is a part of the real level, while the two are actually dissociated. On the other hand, Clark's (1996) layered discourse approach to dramatic interactions (and other conversational phenomena, which are irrelevant here) hinges on layers (or domains) of action dependent on participants, their roles and acts, the place, the time, and features of the situation. Following Clark's (1996) three-layered approach to novels and theatrical plays, one may propose that interpreting film discourse, the viewer engages in a joint pretence with the film crew that what is presented on the screen is actually taking place (cf. Bubel 2008). Specifically, layer 3 represents a given interaction on the screen, layer 2 entails pretending that layer 3 is taking place, and layer 1 entails joint action of the viewer and the film production crew.

New parlance is advocated here to capture the peculiar nature of film discourse, notably its construal and communicative levels. The concepts propounded here are the inter-character/characters' (communicative) level and the recipient's (communicative) level, on which meanings are communicated to the viewer. Additionally, two distinct layers must be distinguished, the fictional world and the underlying multifold layer comprised of sublayers coinciding with cinematographic techniques (scriptwriting, acting, directing, camerawork, editing, etc.) rendered by the collective sender. The recipient's level affords a bird's-eye view 
of the inter-character level, yet having been earlier modified by the collective sender via cinematographic techniques within sublayers. The collective sender controls characters' interactions before and when they take place (determining the form and content of conversations, which are created by the scriptwriter and rendered by actors under the director's supervision) and after they have been performed, (determining how the interactions are shown thanks to picture and sound editing, for instance). Meanings gleaned by audiences are constructed both by actors who verbalise the lines written by scriptwriters under the director's supervision and by means of an array of cinematographic ploys, which can be viewed as what Clark and Van Der Wege (2001) dub mimetic props, i.e. devices which facilitate imagining the story world. The multimodal film discourse is engendered by a wide variety of cinematographic techniques (e.g. Mulvey 1975, Katz 1991), for example with the sound editing and camera movements manipulating the recipient's perception of interactions. From the perspective of linguistic studies, to which the present paper subscribes, the most vital is the discourse overtly produced by fictional interactants but actually materialsed by the film crew.

The characters' level displays interactional patterns of participation typical of ordinary conversations. Each utterance/turn partaking in an interaction is produced by the speaker and directed towards the addressee, and optionally heard by a third party and/or overheard by unratified participants all the three being hearers (listeners) on the characters' level (see Dynel 2010a, 2011e).

On the second communicative level, meanings emerging from film discourse are communicated to the audience. Although viewers witness conversations carried out by unknowing fictional conversationalists, i.e. characters, their participation is planned within the collective sender's layer, determining in various respects how these unknowing characters interact on the screen. To reformulate, characters' interactions interpreted by recipients are the products of the whole film production team, who are aware of recipients, and convey meanings especially for their benefit. On the other hand, it can hardly be argued that recipients consciously interact with the collective sender. Unless they are metarecipients, viewers willingly forget about the real production layer and become preoccupied with characters' communication. From recipients' vantage point, actors merge with the characters they perform, i.e. interactants who live in the make-believe reality of the film and who come over as being the actual authors of the words produced.

Concerning the two communicative levels, it emerges that meanings communicated between characters "become messages about the characters at the level of discourse which pertains between author and reader/audience" (Short 1989: 146). Participating in all encounters shown on the screen, the audience usually enjoy greater knowledge than each character in isolation and/or are presented with facts to which the latter are oblivious. Inasmuch as recipients usually have broader knowledge about the characters in various interactions, their interpretation of dialogues and polylogues may differ from fictional conversationalists' inferences. In other words, the recipient may regard a character or his/her words differently 
when compared to a particular hearer at the characters' level, which creates a mismatch between the inference made by the addressee or third party (cf. Dynel 2010a, 2010b) and that made by the recipient. On the other hand, the viewer may make an additional inferential effort to apprehend meanings generated at the inter-character level and their interpersonal ramifications. For instance, in "Atonement" characters' reciprocal evaluations are divergent from the opinions the viewer holds of them. Secretly sweet on, and jealous of, Robbie, who has an affair with her sister (Cecilia), the teenage Briony falsely accuses the young man of rape and casts a blight on him. As a result, he is stigmatised and hapless for the rest of his life. Whereas the recipient regards Briony as a deceitful spoilt brat, and Robbie as an innocent scapegoat, the whole family (perhaps except for Cecilia) seems to perceive her sister as a trustworthy witness and Robbie as a wayward miscreant. Robbie, on the other hand, must deem Briony as a silly, mendacious child. Although a viewer can conjecture respective characters' opinions of one another, it is only at the end of the film that he/she can comprehend Briony's qualms and the pangs of conscience she has experienced over the years.

Needless to say, speakers in films can hardly address recipients. It is very rarely the case that an actor on the screen addresses an utterance to the viewer, even if notable exceptions of "breaking the fourth wall" can be found. For instance, in "JCVC", featuring Jean Claude Van Damme performing himself, at some point, the character leaves the fictional scene and addresses the audience in a non-fictional monologue. On the other hand, in "Funny Games" or "High Fidelity" protagonists produce asides to the viewer, not abandoning their fictional roles, but acknowledging the audience's presence.

On the other hand, viewers do not contribute verbally to fictional conversational interchanges (cf. Short 1981/1989). Mass media communication, on the whole, is one-way communication (Morris and Ogan 1996, Jucker 2003), with audience's participation being restricted to recipientship. In this respect, viewers are then ratified participants who can be compared to Duncan's (1974) permanent auditors, i.e. participants who never claim the speaking turn. This, however, does not mean that viewers are passive. Verbally passive though they may be, recipients are otherwise active participants, with film discourse being open to their interpretation (cf. Hobson 1982; Duranti 1986; Morley 1980, 1994). On the whole, audiences actively access the medium, interact with producers of the media product, while the latter also probe audiences' interests and interpretations. Jucker (2003) dubs these levels of interaction "interactivity", "interaction" and "feedback", respectively.

\section{Recipient design and recipient's inferential processes}

Each utterance, together with its media rendition, is the collective sender's product directed at the higher-order hearer, viz. the recipient, who duly conducts complex inferential processes on the basis of the information provided and his/ 
her background knowledge. Although viewers may not have full awareness of characters' lives and do not have full insight into their personalities (Bubel 2008), all relevant information must be available to them so that they can make all necessary inferences, as intended by the collective sender. This is because film reality is forged for, and thus by nature available to, viewers. For instance, as earlier argued, recipients have a broader perspective and more extensive knowledge than each character, partaking in all interactions presented. If any interactions or specific meanings are covert from recipients' perspective, this will be because of an underpinning goal on the collective sender's part, such as springing a surprise on viewers or generating suspense. All this is encompassed by the concept of recipient design. A similar concept is known in literature as audience design (Bell 1984, 1991, Clark and Carlson 1982) or overhearer's design (Bubel 2008), which account for particular communicative strategies adjusted to the needs of listeners to a chosen discourse type. For example, Bell $(1984,1991)$ proposes an audience design for news media, according to which speakers adjust their speech styles to match the audience's needs. Adjusting procedures are commensurate with the degree the speaker recognises and ratifies the audience, in the context of a number of sociolinguistic variables, inclusive of pronunciation patterns. Sacks et al. (1974) are, admittedly, the first authors to have developed the notion in reference to how meanings are constructed for hearers in everyday conversations.

"By 'recipient design' we refer to a multitude of respects in which the talk by a party of a conversation is constructed or designed in ways which display an orientation or sensitivity to the particular other(s) who are the co-participants [...] with regard to word selection, topic selection, admissibility, and ordering of options, sequences and obligations for starting and terminating conversations." (Sacks et al. 1974: 727)

Here, the proposal is transported to another level, with the viewer being the recipient, who must be capable of inferring meanings conveyed on the screen. Recipient design is here understood as a set of discursive (as well as cinematographic) techniques enabling the target viewer's interpretative processes and arrival at meanings, in accordance with the collective sender's plan. The latter's choice of strategies, and effects consequent upon them, are dependent on the presupposed target audience. For instance, European highbrow dramas, available to restricted audience, will necessitate complex inferences, while cartoons directed to young audiences must be less cognitively demanding and more entertaining. Nota bene, too easy an inferential path (typical of low-quality films) frequently leads the viewer to a conclusion that conversations are wooden or that the portrayal of characters is lacking in psychological depth.

An understanding of interactions and interactants involves an interface between the media product and viewers' prior knowledge, which affects their perception of the cues provided (Culpeper 2001, 2002). The role of recipients is to 
draw inferences on the basis of limited common ground (Stalnaker 1978, Karttunen and Peters 1979) with characters, embracing communal common ground held by members of a given society and personal common ground developed by individuals in their interactions, as well as the current common ground, i.e. that generated by consecutive utterances within a particular communicative exchange (Clark and Marshall 1981; Clark and Schaefer 1987, 1992; Clark 1996). While common ground of the current and communal types may be unproblematic, recipients share only some part of personal common ground with film characters, who have their history co-constructing their identities, of which recipients cannot be cognisant. Therefore, Bubel argues that viewers can only "conjecture" (cf. Clark and Schaefer 1987) communicative import of characters' turns by "reconstructing the common ground that the speaker presupposes such that the hearer can use the utterance to expand the common ground, thereby giving the utterance a reasonable interpretation" (Bubel 2008: 63). However, it should be emphasised that the collective sender equips viewers with all the knowledge necessary for the latter to reconstruct conversationalists' common ground, and hence the messages relayed, relationships depicted and identities constructed.

The collective sender's intention is that recipients should let themselves be absorbed by the story and the world of the characters, together with their identities and relationships depicted. Thus, during the screening, recipients ought to suspend their awareness of watching a film. Films encourage the suspension of disbelief, and "sustain the illusion that the viewer is observing the action as a fly on the wall" (Kozloff 2000: 47). As a matter of fact, novels, plays, and most significantly, films

"are judged in part by how well they enable us to imagine the highest current layer - how well they transport us into the worlds of the stories. If an adventure story is good, we imagine its world so vividly that it is like a movie running off in our heads." (Clark 1996: 366)

Thanks to various cinematographic ploys, primarily editing, viewers nurture the feeling of reality, as if the events were actually happening. This stands in contrast to what happens in the theatre. Admittedly, theatre goers can hardly indulge themselves in the fictional world, holding a backgrounded assumption that they are in the auditorium. This may be because the action is not so absorbing, but also because the rendition of stage performances is hardly ever reminiscent of everyday encounters. Paradoxically, plays do resemble everyday encounters (more than films) in that they take place in one setting, rather than move swiftly from one location to another; the viewer has one perspective of the ongoing interaction; and there are no technical embellishments found in films. Nonetheless, it is cinematographic ploys (mobile camera, sound and picture editing among other issues) that guarantee the illusion of reality. Watching a film, viewers should, and frequently do, get so engrossed that they forget they are sitting in a cinema or in front of the TV screen. This suspension of awareness of what they are doing is 
not mutually exclusive with recipients' backgrounded understanding that a film is only a cultural artefact and that the characters' portrayal, together with their trials and tribulations, are fictional (even if based on facts in the case of biographical films). However, this understanding is gradable and varies for recipients. For instance, young children tend to watch films (and even cartoons) gullibly, believing their plots to present real events. Even adults will let themselves be absorbed in a gripping story and respond emotionally to the events presented.

Watching a film is an act of joint pretence (cf. Chothia 1978, Clark 1996). Viewers willingly forget that they are interpreting fictional discourse, pretending that the events are actually taking place in front of them and within their earshot. As Clark and Van Der Wege (2001: 783) define it, a joint pretence is "an activity in which two or more people jointly act as if they were doing something that they are not actually, really, or seriously doing at the moment." Joint pretence may then serve as a framework for analysing fictional discourse of books and films (Goffman 1974, Walton 1990, Clark 1996, Clark and Van Der Wege 2001). Film reality subscribes to a coherently constructed fictional frame, in which even the most peculiar illogicalities or impossibilities do not go against the grain, the science-fiction genre typifying this claim. For instance, having assumed that cars may transform into vehement robots ("Transformers"), the viewer never questions their extraordinary capacity and capabilities. On the other hand, some issues are backgrounded and not evoked as relevant, for instance that a female protagonist sports impeccable make-up, irrespective of having spent four days in a desert, with no access to any bathroom, let alone cosmetics. What the viewer stands a stronger chance of observing, however, is an illogicality which violates any of the pivotal premises of a fictional frame, which is an oversight on the film crew's part, e.g. that the characters do not use the car they have but keep walking on foot. In conclusion, recipients follow the interpretative paths forged by the collective sender, pretending, for the duration of the film, that what they see on the screen is actually happening.

Additionally, viewers follow the principles of imagination and appreciation proposed for "non-serious discourse" of films (Clark 1996). The principle of imagination in the context of film discourse amounts to viewing the media product as if it presented ordinary events, characters and relations between them. On the other hand, the principle of appreciation entails understanding the product and recognising the purpose of each message and the vehicles by means of which it is conveyed. Bubel claims that appreciation

"illustrates how the audience is involved in the co-construction of meaning. It comprises what the audience does on the lower, more obscure layers, such as when they recognize how screenwriters and film directors, camera and editing staff achieve certain effects." (2008: 60)

As regards verbalisations, appreciation thereof will entail comprehending characters' utterances, whether couched in literalness or implicitness, and their emer- 
gent meanings. Nonetheless, a major question arises as to whether the recipient does appreciate consciously the rhetorical strategies employed by interlocutors (and actually by the scriptwriter) or the whole gamut of cinematographic techniques. More likely, the recipient conducts interpretative processing of film discourse intuitively, familiar with recurrent patterns typical of film genres (Hedges 1991). Appreciation processes will thus frequently proceed automatically, below the viewer's awareness threshold, unless inferences are cognitively demanding, as in the case of crime stories or highbrow films. As already suggested, appreciation processes are determined by the nature of a film, as well as idiosyncratic perceptions of viewers, who may display varied intellectual capacity and expertise. Admittedly, while some meanings are available to wide audiences, generating other meanings may be more effortful, to the extent of their being elusive. An example here is the output of Quentin Tarantino, whose films can be read differently depending on the viewer's expertise. Oblivious to his recurrent ploys, a viewer may watch "Kill Bill" or "Deathproof", without appreciating the richness of subversive allusions to earlier films and other artefacts of popular culture. Because of this, the films may appear rather superficial or devoid of much sense to some, while being regarded as ingenious by those in the know.

It could be argued that since the appreciation of cinematographic and discursive techniques shows gradability, the distinction between the recipient and the metarecipient is blurry. Nevertheless, a lay recipient watches a film primarily for pleasure and entertainment (but may simultaneously appreciate the means by which certain effects are promoted). The extreme case of sensitivity to mimetic vehicles is that of the metarecipient, who concentrates not (or at least not only) on imagination but on appreciation processes, and consciously analyses chosen aspects of film discourse with a view to understanding its workings. For instance, recognising visual techniques by which a given effect is fostered frequently entails expertise in cinematography. It is, in all likelihood, not the case that all viewers will appreciate that some meaning is conveyed by, for example, a close-up. However, they will infer, or even take for granted, a particular character's sincerity, consequent upon the application of this cinematic ploy. Similarly, decoding verbal messages does not normally demand pondering on the rhetorical figures which promote them. The meanings should simply be grasped, even if with additional cognitive effort. On the other hand, a metarecipient's scholarly investigation into film discourse necessitates paying heed to chosen aspects of verbalisations, their form, functions and mechanisms (e.g. pragmatic or cognitive).

Finally, it should be borne in mind that there may be variability in viewers' negotiated readings of film discourse, depending on their social and historical background (Neale 1977, Hall 1980, Morley 1980, Hobson 1982, Ang 1985, Palmer 1986, Fiske 1986). This will be relevant perhaps not so much in the case of basic understanding of utterances or the plot, which should be equivocal by design (otherwise resulting in miscomprehension/lack of comprehension), but as regards the construction of global ideological meanings. Those may indeed be dependent on viewers' experience, knowledge or prejudices, as well as their intellectual 
capacity. This is the case of audiences' construing, for instance, gendered identity conceptualisations. Admittedly, the selfsame problems will emerge in the case of everyday interactions. Dow (1996: 3) rightly perceives the single vs. collective decoding problem, arguing that film interpretation is

"always the product of socially situated persons who make arguments that are enabled but also limited by their experiences and perspectives. However, there is no such thing as the totally isolated, individualistic, idiosyncratic reading of a text." (Dow 1996: 3)

In essence, target recipients of a given film read texts in a similar manner, prototypically coinciding with the collective sender's intention. Admittedly, in most language studies, an ideal picture of communication will be taken into account, with viewers' misinterpretations being marginalised.

\section{Summary}

The article aimed to shed light on a number of methodological issues germane to linguistic research on film discourse. A statement was ventured that, its peculiar features notwithstanding, film discourse bears similarity to real discourse and lends itself to linguistic investigation. Language studies may draw on film discourse with a view to validating theoretical models or demonstrating the workings of fictional communication. Moreover, it was suggested that characters' identity construction research may subscribe to linguistic studies. On the whole, collective senders normally do their utmost to guarantee that fictional characters, with their fictional idiolects and identities, should not come over as untenable.

Secondly, attention was devoted to the inherently twofold fictional and nonfictional layering of film discourse, as well as two communicative levels: the level of characters, reminiscent of everyday interactions, and the level at which the global media product is directed to the recipient. The latter appreciates it by willingly pretending that he/she is watching and listening to real interactions. Diversified methods of creating this illusion can be appreciated by the metarecipient, i.e. the informed recipient. Essentially, dialogues and polylogues develop in such a way as to allow the audience to appreciate the messages, characters and relationships between them, as envisaged by the collective sender.

Film discourse deserves to be extensively investigated by linguists. Fictional discourse is not strange and should not be treated as if it were.

\section{Notes}

1 Technically, scripted conversation may also embrace discourse types which are not fictional per se, such as the discourse of entertainment TV programmes, which are scripted even if 
interlocutors can paraphrase the scripted text or entwine spontaneous utterances with it.

Not all characters must be fictional per se, a case in point being historical figures. However, their portrayal in films is largely fictional, albeit plausible, especially in terms of the utterances they produce, which is of central attention here.

\section{References}

Ang, Ien (1985) Watching Dallas: Soap Opera and the Melodramatic Imagination. London: Methuen,

Antaki, Charles and Sue Widdicombe (1998) Identitites in Talk. London: Sage.

Aumont, Jacquesm Alain Bergala, Michel Marie and Marc Vernet (1992) Aesthetics of Film, translated by Richard Neupert. Austin: University of Texas Press.

Bell, Allan (1984) 'Language style as audience design'. Language and Society 13, 145-204.

Bell, Allan (1991) The Language of News Media. Oxford: Blackwell.

Bennison, Neil (1993) 'Discourse analysis, pragmatics, and the dramatic character: Tom Stoppard's Professional Foul'. Language and Literature 2, 79-99.

Berger, Arthur (1992) Popular Culture Genres: Theories and Texts. London: Sage,

Berliner, Todd (1999) 'Hollywood movie dialogue and the 'real realism' of John Cassavetes'. Film Quarterly 52, 2-16.

Bignell, Jonathan (2002) Media Semiotics: An Introduction. Manchester: Manchester University Press.

Bordwell, David and Kristin Thompson (1979) Film Art. Madison: McGraw-Hill.

Boxer, Diana (2002) Applying Sociolinguistics: Domains of Face-to-Face Interaction. Amsterdam: Benjamins.

Bubel, Claudia (2006) The linguistic construction of character relations in TV drama: doing friendship in Sex and the City. Unpublished PhD Thesis. Saarbrucken: Universitat des Saarlandes.

Bubel, Claudia (2008) 'Film audiences as overhearers'. Journal of Pragmatics 40, 55-71.

Bubel, Claudia and Alice Spitz (2006) 'One of the last vestiges of gender bias: The characterization of women through the telling of dirty jokes in Ally McBeal'. Humor 19, 71-104.

Bucholtz, Mary and Kira Hall (2005) 'Identity and interaction: A sociocultural linguistic approach'. Discourse Studies 7, 584-614.

Burger, Harald (1984) Sprache der Massenmedien. Berlin: de Gruyter.

Burger, Harald (1991) Das Gesprach in den Massenmedien. Berlin: de Gruyter.

Carter Ronald and Paul Simpson (1979) Language, Discourse, and Literature. London: Routledge.

Chothia, Jean (1978) Forging a Language: A Study of Plays of Eugene O'Neill. Cambridge: Cambridge University Press.

Chovanec, Jan (2011) 'Humour in quasi-conversations: Constructing fun in online sports journalism'. In: Dynel, Marta (ed.) The Pragmatics of Humour across Discourse Domains, 243-264.

Clark, Herbert (1996) Using Language. Cambridge: Cambridge University Press.

Clark, Herbert and Thomas Carlson (1982) 'Hearers and speech acts'. Language 58, 332-372.

Clark, Herbert and Catherine R. Marshall (1981) 'Definite reference and mutual knowledge'. In: Joshi, A.K., B. Webber, and I. Sag (eds.) Elements of Discourse Understanding. Cambridge: Cambridge University Press, 10-63.

Clark, Herbert and Edward Schaefer (1987) 'Concealing one's meaning from overhearers'. Journal of Memory and Language 26, 209-225.

Clark, Herbert and Edward Schaefer (1992) 'Dealing with overhearers'. In: Clark, Herbert (ed.) Arenas of Language Use. Chicago: University of Chicago Press, 248-273.

Clark, Herbert and Mija Van Der Wege (2001) 'Imagination in discourse' In: Schiffrin, Deborah, Deborah Tannen and Heidi E. Hamilton (eds.) The Handbook of Discourse Analysis. Oxford: Blackwell, 772-786.

Cooper, Marilyn (1981) 'Impoliteness, convention and the taming of the shrew'. Poetics 10, 1-14. 
Culler, Jonathan (1975) Structuralist Poetics: Structuralism, Lingusitics and the Study of Literature. London: Routledge \& Kegan Paul.

Culpeper, Jonathan (2001) Language and Characterisation: People in Plays and Other Texts. London: Longman.

Culpeper, Jonathan (2002) 'A cognitive stylistic approach to characterisation'. In: Semino, Elena and Jonathan Culpeper (eds.) Cognitive Stylistics: Language and Cognition in Text Analysis. Amsterdam: Benjamins, 251-277.

Dow, Bonnie (1996) Prime-Time Feminism. Television, Media Culture and the Women's Movement. Philadelphia: University of Pennsylvania Press.

Downes, William (1988) 'King Lear's question to his daughters'. In: Peer, Willie van (ed.) The Taming of the Text: Explorations in Language Literature and Culture. London: Routledge, 225-257.

Duncan, Starkey (1974) 'On the structure of speaker-auditor interaction during speaking turns'. Language in Society 3, 161-180.

Duranti, Alessandro (1986) 'The audience as co-author: An introduction'. Text 6, 239-247.

Dynel, Marta (2009) Humorous Garden-Paths: A Pragmatic-Cognitive Study. Newcastle: Cambridge Scholars Publishing.

Dynel, Marta (2010a) 'Friend or foe? Chandler's humour from the metarecipient's perspective'. In: Witczak-Plisiecka, Iwona (ed.) Pragmatic Perspectives on Language and Linguistics Vol. II: Pragmatics of Semantically Restricted Domains. Newcastle: Cambridge Scholars Publishing, 175-205.

Dynel, Marta (2010b) 'Not hearing things - Hearer/listener categories in polylogues'. mediAzioni 9. http://mediazioni.sitlec.unibo.it.

Dynel, Marta (2011a) 'A potluck approach to Polish comedies: Towards determining the Polish taste culture'. In: Brzozowska, Dorota and Władysław Chlopicki (eds.) Polish Humor. Kraków: Tertium.

Dynel, Marta (2011b) 'Entertaining and enraging: The functions of verbal aggression in political debates'. In: Tsakona, Villy and Diana Popa (eds.) Confronting Power with Laughter.

Dynel, Marta (2011c) 'Two communicative levels and twofold illocutionary force in televised political debates. 'Poznan Studies in Contemporary Linguistics 47(2), 283-307.

Dynel, Marta (2011d) 'Women who swear and men who fret: The subversive construction of genders in films: A case study of "Lejdis" and "Testosteron"'. In: Gonerko-Frej et al. (eds.) Us and Them - Them and Us: Constructions of the Other in Cultural Stereotypes - Perceptions, Challenges, Meanings. Shaker Verlag.

Dynel, Marta (2011e) 'You talking to me?' The viewer as a ratified hearer.' Journal of Pragmatics 43, 1628-1644.

Emmison, Michael (1993) 'On the analyzability of conversational fabrication: A conceptual inquiry and single case example'. Australian Review of Applied Linguistics 16, 83-108.

Emmison, Michael and Laurence Goldman (1996) 'What's that you said sooty? Puppets, parlance and pretence'. Language and Communication 16, 17-35.

Emmott, Catherine (1997) Narrative Comprehension: A Discourse Perspective. Oxford: Oxford University Press.

Fetzer, Anita (2006) “"Minister, we will see how the public judges you”. Media references in political interviews'. Journal of Pragmatics 38, 180-195.

Fiske, John (1986) 'Television: Polysemy and popularity'. Critical Studies in Mass Communication 3, 391-408.

Fiske, John and John Hartley (1978) Reading Television. London: Methuen.

Fokkema, Aleid (1991) Postmodern Characters: A Study of Characterization in British and American Postmodern Fiction. Amsterdam: Rodopi.

Frye, Northrop (1957) Anatomy of Criticism: Four Essays. Princeton: Princeton University Press.

Garfinkel, Harold (1967) Studies in Ethnomethodology. Englewood Cliffs, NJ: Prentice Hall.

Garvey, James (1978) 'Characterization in narrative'. Poetics 7, 63-78.

Gauntlett, David (2002) Media, Gender and Identity: An Introduction. London: Routledge 
Georgakopoulou, Alexandra (2000) 'On the sociolinguistics of popular cinema: funny characters, funny voices'. Journal of modern Greek Studies 19, 119-133.

Giannetti, Louis (2007) Understanding Movies, $11^{\text {th }}$ ed. Reihe: Allyn \& Bacon.

Goffman, Erving (1974) Frame Analysis: An Essay on the Organization of Experience. New York: Harper and Row.

Goffman, Erving (1981) Forms of Talk. Philadelphia: University of Pennsylvania Press.

Greimas, Algirdas (1983) Structural Semantics, translated by Daniele McDowell, Lincoln: University of Nebraska Press [(1966) Semantique Structurale. Paris: Larousse]

Hall, Stuart (1980) 'Encoding/Decoding' In: Hall, Stuart, Dorothy Hobson, Andrew Lowe and Paul Willis (eds.) Culture, Media, Language: Working Papers in Cultural Studies. London: Hutchinson, 128-39.

Hall, Kira and Beth Daniels (1992) “'It's rather like embracing a textbook": The linguistic representation of the female psychoanalyst in American film'. In: Hall, Kira, Mary Bucholtz and Birch Moonwomon (eds.) Locating Power: Proceedings of the second Berkeley Women and Language Conference. Berkeley: Berkeley Women and Language Group, 223-239.

Harvey, William (1965) Character and the Novel. London: Chatto and Windus.

Hedges, Inez (1991) Breaking the Frame: Film Language and the Experience of Limits. Indiana University Press.

Hedley Mark. (2002) 'The geometry of gendered conflict in popular film: 1986-2000'. Sex Roles 47, 201-217.

Herman, Vimala (1995) Dramatic Discourse: Dialogue as Interaction in Plays. London: Routledge.

Hobson, Dorothy (1982) Crossroads: The Drama of a Soap Opera. London: Methuen.

Hopper, Robert and Curtis Le Baron (1999) 'How gender creeps into talk'. Research on Language and Social Interaction 31, 59-74.

Hurst, Daniel (1987) 'Speech acts in Ivy Compton-Burnett's A Family and a Fortune'. Language and Style 20, 342-358.

Hutchby, Ian. 2006. Media Talk: Conversation Analysis and the Study of Broadcasting.

Glasgow: Open University Press.

Jucker, Andreas, H. (2003) 'Mass media communication at the beginning of the twenty-first century. Dimensions of change'. Journal of Historical Pragmatics 4, 129-148.

Karttunen, Lauri and Stanley Peters (1979) 'Conventional implicature'. In: Oh, Choon-Kyu and David A. Dinneen (eds.) Syntax and Semantics: Presupposition. New York: Academic Press, $1-56$.

Katz, Steve (1991) Film Directing Shot by Shot: Visualizing from Concept to Screen. Michael Wiese Productions.

Kerbrat-Orecchioni, Catherine (1997) 'A multilevel approach in the study if talk-in-interaction'. Pragmatics 7, 1-20.

Kerbrat-Orecchioni, Catherine (ed.) (2004) 'Polylogue'. Journal of Pragmatics 36 (Special Issue), $1-145$.

Kozloff, Sarah (2000) Overhearing Film Dialogue. Berkeley: University of California Press.

Lakoff, Robin (1990) Talking Power: The Politics of Language. New York: Basic Books.

Lorenzo-Dus, Nuria (2009) Television Discourse. Analysing Language in the Media. Basingstoke and New York: Palgrave Macmillan.

Lowe, Valerie (1998) “"Unhappy” confessions in The Crucible: A pragmatic explanation'. In: Culpeper, Jonathan, Mick Short and Peter Verdonk (eds.) Exploring the Language of Drama: From Text to Context. London: Routledge, 128-141.

Margolin, Uri (1983) 'Characterisation in narrative: Some theoretical prolegomena'. Neophilologus $67,1-14$.

Margolin, Uri (1996) 'Characters and their versions'. In: Mihailescu, Calin Andrei and Walid Hamarneh (eds.) Fiction Updated: Theories of Fictionality, Narratology, and Poetics. Toronto: University of Toronto Press, 113-32. 
Martin, James and Peter White (2005) The Language of Evaluation: Appraisal in English. London: Palgrave.

McHoul, Alec (1987) 'An initial investigation of the usability of fictional conversation for doing conversational analysis'. Semiotica 67, 83-104.

Mead, Gerald (1990) 'The representation of fictional character'. Style 24, 440-452.

Monaco, James (1981) How to Read a Film: The World of Movies, Media, Multimedia: Language, History, Theory. Oxford University Press.

Morley, David (1980) The Nationwide Audience: Structure and Decoding. London: British Film Institute.

Morley, David (1994) 'Active audience theory: Pendulums and pitfalls'. In: Levy, Mark R. and Michael Gurevitch (eds.) Defining Media Studies: Reflections on the Future of the Field. Oxford: Oxford University Press, 255-261.

Morris, Merrill and Christine Ogan (1996) 'The Internet as a mass medium'. Journal of ComputerMediated Communication 1.4 (http://www.ascusc.org/jcmc/vol1/issue4/morris.html).

Mulvey, Laura (1975) 'Visual pleasure and narrative cinema'. Screen 16/3, 6-18. Reprinted in: Kaplan, A.E. (ed.) (2000) Feminism and Film. New York: Oxford University Press, 34-47.

Neale, Stephen (1977) 'Propaganda'. Screen 18, 9-40.

Newcomb, Horace and Paul Hirsch (1987) 'Television as a cultural forum'. In: Newcomb, Horace (ed.) Television: The critical view, 4th ed. New York: Oxford University Press, 453-470.

O'Keeffe, Anne (2006) Investigating Media Discourse. London: Routledge.

Palmer, Patricia (1986) The Lively Audience: A Study of Children around the TV Set. Sydney: Allen \& Unwin.

Palmer, Alan (2002) 'The construction of fictional minds'. Narrative 10.1, 28-46.

Palmer, Alan (2004) Fictional Minds. Lincoln: University of Nebraska Press.

Payrató, Luis (2009) 'Non-verbal communication'. In: Verschueren, Jeff and Jan-Ola Östman (eds.) Key Notions for Pragmatics. Amsterdam/Philadelphia: John Benjamins, 163-194.

Phelan, James (1979) Reading People, Reading Plots: Character, Progression, and the Interpretation of Narrative. Chicago: University of Chicago Press.

Pratt, Mary (1977) Towards a Speech Act Theory of Literary Discourse. Bloomington: Indiana University Press.

Propp, Vladimir (1968) Morphology of the Folktale, $2^{\text {nd }}$ ed, translated by L. Scott. Austin: University of Texas Press.

Quaglio, Paulo (2008) 'Television dialogue and natural conversation: Linguistic similarities and functional differences.' In: Ädel, Annelie and Randi Reppen (eds.) Corpora and Discourse: The Challenges of Different Settings. Amsterdam/Philadelphia: John Benjamins, 189-210.

Quaglio, Paulo (2009) Television Dialogue: The Sitcom Friends vs. Natural Conversation. Amsterdam/Philadelphia: John Benjamins.

Richardson, Kay (2010) Television Dramatic Dialogue. A Sociolinguistic Study. New York: Oxford.

Rose, Kenneth (2001) 'Compliments and compliment responses in film: Implications for pragmatics research and language teaching'. International Review of Applied Linguistics 39, 309-326.

Sacks, Harvey, Emanuel Schegloff and Gail Jefferson (1974) 'A simplest systematics for the organisation of turn-taking for conversation'. Language 50, 696-735.

Scannell, Paddy (1991) 'Introduction: The relevance of talk'. In: Scannell, Paddy (ed.) Broadcast Talk. Sage, London, 1-13.

Schegloff, Emanuel (1988) 'Goffman and the analysis of conversation'. In: Drew, Paul and Anthony Wotton (eds.) Erving Goffman: Exploring the Interaction Order, Oxford: Polity Press, 89-135.

Scholes, Robert and Robert Kellogg (1966) 'Character in narrative'. In: Scholes, Robert and Robert Kellogg (eds.) The Nature of Narrative. London: Oxford University Press, 160-206.

Schwarz, Daniel (1989) 'Character and characterization: An inquiry'. The Journal of Narrative Technique 19(1), 85-105.

Semino, Elena (2002) 'A Cognitive stylistic approach to mind style in narrative fiction'. In: Semino, Elena and Jonathan Culpeper (eds.) Cognitive Stylistics. Amsterdam: Benjamins, 95-122. 
Short, Mick (1981) 'Discourse analysis and the analysis of drama'. Applied Linguistics 2, 180-202. Reprinted in: Carter, Ronald and Paul Simpson (eds.) (1989) Language, Discourse, and Literature. Unwin Hyman Ltd, 137-168.

Short, Mick (1994) 'Discourse analysis and drama'. In: Asher, R.E. (ed.) The Encyclopedia of Language and Linguistics. Oxford: Pergamon, 949-952.

Short, Mick (2007) 'How to make a drama out of a speech act: The speech act of apology in the film A Fish Called Wanda'. In: Hoover, David L. and Sharon Lattig (eds.) Stylistics: Retrospect and Prospect. Amsterdam: Rodopi, 169-189.

Simpson, Paul (1998) 'Odd talk: Studying discourses of incongruity'. In: Culpeper, Jonathan, Mick Short and Peter Verdonk (eds.) Exploring the Language of Drama: From Text to Context. London: Routledge, 34-53.

Stalnaker, Robert (1978) 'Assertion'. In: Cole, Peter (ed.) Syntax and Semantics: Pragmatics, NY: Academic Press, 315-332.

Stam, Robert (2000) Film Theory: An Introduction. Oxford: Blackwell,

Tannen, Deborah (1984) Conversational Style. Analyzing Talk among Friends. Norwood, NJ: Newbury House.

Tannen, Deborah and Robin Lakoff (1994) 'Conversational strategy and metastrategy in a pragmatic theory: The example of scenes from a marriage'. In: Tannen, Deborah (ed.) Gender and Discourse. Oxford: Oxford University Press, 137-173.

Toolan, Michael (1988) Narrative: A Critical Linguistic Introduction. London: Routledge.

Turner John and Penelope Oakes (1989) 'Self-categorization theory and social influence'. In: Paulus, Paul (ed.) The Psychology of Group Influence. Hillsdale, N. J.: Erlbaum, 233-275.

van Peer, Willie (1989) The Taming of the Text: Explorations in Language, Literature and Culture. London: Routledge.

Walcutt, Charles Child (1966) Man's Changing Mask: Modes and Methods of Characterization in Fiction. Minneapolis: University of Minnesota Press.

Walton, Kendall (1990) Mimesis as Make-Believe: On the Foundations of the Representational Arts. Harvard: Harvard University Press.

Weatherall, Ann (1996) 'Language about women and men: An example from popular culture'. Journal of Language and Social Psychology 15, 59-75.

Marta Dynel is an assistant professor in the Department of Pragmatics in the Institute of English at the University of Łódź. She has published internationally in linguistic journals and volumes. Her research interests are primarily in pragmatic, cognitive and sociolinguistic mechanisms of humour, neo-Gricean studies, (im)politeness, as well as in the methodology of film discourse analysis, notably the pragmatics of interaction.

Address: Dr Marta Dynel, University of Łódź, Department of Pragmatics, Institute of English, Al. Kościuszki 65, 90-514 Łódź, Poland. [email: marta.dynel@yahoo.com] 
